Article

\title{
Algorithmic Allocation: Untangling Rival Considerations of Fairness in Research Management
}

\author{
Guus Dix ${ }^{1, *}$, Wolfgang Kaltenbrunner ${ }^{1}$, Joeri Tijdink ${ }^{2,3}$, Govert Valkenburg ${ }^{4}$ and Sarah de Rijcke ${ }^{1}$ \\ ${ }^{1}$ Centre for Science and Technology Studies, Leiden University, 2311 EZ Leiden, The Netherlands; \\ E-Mails: g.dix@cwts.leidenuniv.nl (G.D.),w.kaltenbrunner@cwts.leidenuniv.nl (W.K.), \\ s.de.rijcke@cwts.leidenuniv.nl (S.d.R.) \\ ${ }^{2}$ Department of Medical Humanities, AmsterdamUMC, location VUmc, 1081 HV Amsterdam, The Netherlands; \\ E-Mail: jk.tijdink@amsterdamumc.nl \\ 3 Department of Philosophy, Vrije Universiteit Amsterdam, 1081 HV Amsterdam; The Netherlands \\ 4 Department of Interdisciplinary Studies of Culture, Norwegian University of Science and Technology, 7491 Trondheim, \\ Norway; E-Mail: govert.valkenburg@ntnu.no
}

* Corresponding author

Submitted: 30 October 2019 | Accepted: 30 December 2019 | Published: 9 April 2020

\begin{abstract}
Marketization and quantification have become ingrained in academia over the past few decades. The trust in numbers and incentives has led to a proliferation of devices that individualize, induce, benchmark, and rank academic performance. As an instantiation of that trend, this article focuses on the establishment and contestation of 'algorithmic allocation' at a Dutch university medical centre. Algorithmic allocation is a form of data-driven automated reasoning that enables university administrators to calculate the overall research budget of a department without engaging in a detailed qualitative assessment of the current content and future potential of its research activities. It consists of a range of quantitative performance indicators covering scientific publications, peer recognition, PhD supervision, and grant acquisition. Drawing on semi-structured interviews, focus groups, and document analysis, we contrast the attempt to build a rationale for algorithmic allocation-citing unfair advantage, competitive achievement, incentives, and exchange-with the attempt to challenge that rationale based on existing epistemic differences between departments. From the specifics of the case, we extrapolate to considerations of epistemic and market fairness that might equally be at stake in other attempts to govern the production of scientific knowledge in a quantitative and market-oriented way.
\end{abstract}

\section{Keywords}

algorithmic allocation; higher education; marketization; performance indicators; quantification; resource allocation

\section{Issue}

This article is part of the issue "Quantifying Higher Education: Governing Universities and Academics by Numbers" edited by Maarten Hillebrandt (University of Helsinki, Finland) and Michael Huber (University of Bielefeld, Germany).

(C) 2020 by the authors; licensee Cogitatio (Lisbon, Portugal). This article is licensed under a Creative Commons Attribution 4.0 International License (CC BY).

\section{Introduction}

Large research organizations need to address a question that is at once moral and technical: How to allocate resources across different departments to effectively foster certain organizational goals and be perceived as generally fair at the very same time. The organization central to this article-a university medical centre-sought the answer to this question in an allocation model based on quantitative performance criteria and departmental competition. More specifically, the Centre intended to 'stimulate the control of the (financial) business operation through the implementation of performance-based financing at the departmental level' and to gauge excellence in research 'based on objective and measurable criteria' such as 'the citation score and impact factor' (doc- 
ument 1; document 5). In 2015 and 2016, the board of directors was engaged in an iterative process of developing an allocation algorithm together with financial controllers and (bio)medical scientists. Algorithmic allocation, as we call it, is a form of quantitative reasoning that makes it possible to calculate the costs and the achievements of a department without engaging in a detailed qualitative assessment of the current content and future potential of its research activities. This form of reasoning did not come out of thin air. In fact, it fits into a history of attempts to induce departments to increase their scientific performance which is underpinned by entrenched ideas of fairness and effectiveness in research management. Entrenched as these ideas might be, the board decided to put the model on hold only two years after it had been introduced. In that short timeframe, algorithmic allocation had become controversial for the way it affected the research capacity of different departments. As one interviewee put it succinctly: 'I think in fact that you do not have a backbone, sort of, when you say: "Yes, we will let the algorithm decide where the money will go to"' (professor 2).

Algorithmic allocation is tied to a particular organizational setting at a particular time and simultaneously linked to more generic developments in higher education-and society at large-such as quantification, marketization, and algorithm-based decision making. Over the past four decades, quantitative performance indicators and market-oriented ideals and practices have become more significant in academia. University rankings, for instance, have re-emerged at the beginning of this millennium at the intersection of private initiatives and a new field of research analytics and secured themselves a strong position in university management (Hammarfelt, de Rijcke, \& Wouters, 2017; Paradeise \& Filliatreau, 2016; Paradeise \& Thoenig, 2018; Sauder \& Espeland, 2009). Beyond managerial contexts, quantitative indicators such as the Journal Impact Factoras a proxy for the quality of scientific journals-and the $\mathrm{H}$-index-as a proxy for the quality of a scientisthave also consolidated themselves on the shop floor of academic research (Rushforth \& de Rijcke, 2015, 2017; Rushforth, Franssen, \& de Rijcke, 2018). The increased emphasis on competition, incentivization, and the economic value of research has led social scientists to speak of 'market universities' and 'epistemic capitalism' as the new academic status quo (Berman, 2012; Birch, 2017; Fochler, 2016; Slaughter \& Rhoades, 2009). Sociologists and new media studies scholars have further explored the ways in which marketization and quantification are tied to increasing automation and algorithmic calculation (Berman \& Hirschman, 2018; Couldry, 2016; Finn, 2017; van Dijck, 2013). In an 'algorithmic culture' (Striphas, 2015), human thoughts and conducts are easily expressed in the logic of big data. These computational practices are further embedded in highly consequential decision-making processes in a wide range of domains: Who should obtain a visa? Who should be con- sidered a risk to society? Who deserves to be rewarded? And which product or service will satisfy our desires? When value is increasingly measured computationally and algorithms inform-or make-decisions, it is imperative to better understand the way algorithms are designed and how they shape public spheres.

This article focuses on higher education as one of the key areas of social life where market-oriented practices, quantitative performance indicators, and algorithmbased decision-making processes have made large inroads. More particularly, it extends the literature discussed above in the direction of the normative considerations that people offer to support or problematize these developments. For whatever their actual consequences, such developments do not take place without attempts being made to support or challenge them. The research question of our article is analytical: Which normative considerations do researchers and administrators draw upon to justify or criticize algorithm-based decision making in academia? We provide an answer to this question based on focus groups, semi-structured interviews, and document analysis. More specifically, we untangle two rival notions of fairness at play in research management: Considerations of 'market fairness' are offered in support of algorithmic allocation whereas considerations of 'epistemic fairness' are offered as a challenge to it (Section 2). Our analysis starts with an overview of the current state of algorithmic allocation at the university medical centre (Section 3). Subsequently, we analyze the construction of a market-oriented justification that merges a critique of 'unfair' privileges with an emphasis on 'fair' competition, incentives, and exchange (Section 4). We conclude our analysis with attempts to challenge algorithmic allocation by those who stress the unfairness of a uniform model given the significant epistemic differences between departments (Section 5). Some people might be more inclined to favour consideration of market fairness over considerations of epistemic fairness (and vice versa). But it is important to keep in mind that the central tension between the two is not only found between relatively fixed sets of actors but also within actors themselves. Based on our analytic distinction, we caution against having a narrow perspective of research organizations as being relatively homogenous entities and mere recipients of broader trends in academia, and furthermore, we offer a set of questions to enable researchers and research managers to think reflexively about algorithm-based decision-making (Section 6).

\section{Conceptualizing Market Fairness and Epistemic Fairness: Theory and Method}

Markets are important economic phenomena but they are equally important for the moral justifications they enable. Sociologists have theorized how markets are linked to particular 'moral views' on what binds people together (Boltanski \& Thevenot, 2006; Fourcade \& Healy, 
2007). Four main aspects of this 'market bond' have been highlighted. Firstly, Boltanski and Thevenot (2006, pp. 196-197) speak of it as a relatively coherent set of normative principles which place much emphasis on 'competition between beings placed in a state of rivalry' and on the value of competitive achievement. Second, to get ahead in a competitive environment, people lend themselves 'willingly to every opportunity to engage in a transaction' and should thus be enabled to exchange goods and services as they see fit (Boltanski \& Thevenot, 2006 , p. 200). The third aspect of the market bond is that competition and exchange should induce people to work for the benefits of others - not just for themselves. In that sense, 'market systems are supposed to provide incentives and opportunities for innovation' (Fourcade \& Healy, 2007, p. 290). Fourth, markets are considered to be a fair allocation system vis-à-vis a system of government interventions that privilege some at the cost of others. Thinking along these lines, 'competitive economic arrangements are the best defence...against arbitrary interference' (Fourcade \& Healy, 2007, p. 290). In our case, 'market fairness' is the analytical term that captures these four normative considerations-competitive achievement, exchange, incentivization, and limiting arbitrary interference-with which researchers and administrators build an organizational rationale to support algorithmic allocation.

Considerations of market fairness are important but not the sole source of normativity. As we briefly discussed, algorithmic allocation quickly became controversial for its practical consequences and its normative underpinnings. Researchers and administrators highlight major differences in the way scientific knowledge is produced in different departments to dispute the alleged fairness of a uniform allocation model. The idea that practices of knowledge production vary greatly is not new to scholars in Science and Technology Studies, an interdisciplinary field of social scientists who study the social, material, and cognitive aspects of scientific inquiry and technological developments. Knorr-Cetina (1999), for instance, has coined the term 'epistemic cultures' to capture differences in the environment, procedures, and objects of different research communities as well as the different affordances and constraints these communities experience (see also Borgman, 2017; Franssen, Scholten, Hessels, \& de Rijcke, 2018; Hessels, Franssen, Scholten, \& de Rijcke, 2019). Following Knorr-Cetina, we can say that a university medical centre is unified in its focus on the understanding, prevention, and treatment of illness but internally divided in terms of the underlying epistemic cultures. The considerations of 'epistemic fairness' we discerned call algorithmic allocation into question by highlighting crucial differences in material costs, technological requirements, access to resources, and collaboration and publication practices.

To analyse rival considerations of fairness in research management, we combined semi-structured interviews with focus groups and document analysis. The first, ex- ploratory research phase of our research project consisted of two focus groups with six early career and eight senior (bio)medical researchers, one interview with the dean and one interview with three research policy advisors. The interviews and focus groups initially zoomed in on ideals of responsible (bio)medical research and on instruments to foster innovative and societally relevant research practices. The analysis of the interview transcripts led to the selection of three main areas of organizational change at the centre: reorganizing research, measuring and visualizing scientific output, and evaluating and rewarding scientists. These three themes were central to the second, more focused research phase. This second phase consisted of eight additional interviews with researchers as well as staff members in key advisory positions within the Centre: two research policy advisors, two financial controllers, and four professors involved in central management. In addition to the analysis of interview transcripts and notes, the article is based on a series of documents that capture different features of research organization, measurement, and evaluation at the Centre: The annual reports on the financial and organizational state of the Centre over an eleven-year period; two five-year plans in which the Centre gives a broad outline of the main developments and strategies in (bio)medical research and healthcare practices; the hiring and promotion procedures for associates and full professors; website material; a dissertation on early developments in resource allocation (not in the bibliography for reasons of anonymity); documents about the new resource allocation model; as well as internal presentations about the model before it was put into practice (see Table 1 for a detailed overview of the interviews and focus groups and the selection of documents used for this study).

\section{Algorithmic Allocation: Towards a Metric-Based Model}

In a very basic form, algorithmic allocation goes back to the very establishment of the medical centre during a wave of mergers between academic hospitals and university-based medical faculties in the late 1990s and early 2000s. At the time, the board of directors decided to put a small part of its research budget in a separate fund from which it was subsequently distributed back to the departments based on two rather straightforward performance criteria: the number of doctorates and the number of 'full-time equivalents' acquired through external funding. That allocation model remained more or less unchanged for over a decade (document 6). Only recently, in 2015 , did the board decide to shift from 'performancebased funding' to 'performance-based financing.' More than a mere semantic change, the intended reform was substantial: '[S]o we moved on by allotting all gains and all costs to the department. And we made a part of it variable, a pretty large part of it at that' (financial controller 1). Two substantial changes stand out. 
First, performance-based financing went far beyond performance-based funding in making departments responsible for the costs they made in conducting their research. In terms of overhead costs, departments were now required to pay the central administration for the use of office and laboratory space-in square metersand for the number of their employees (as a parameter to divide all overhead costs). The integration of such costs into the allocation model was not primarily driven by developments inside the field of (bio)medical research but came primarily from healthcare (financial controller 2). An earlier political push for the marketization of Dutch healthcare had led hospitals to become more sensitive to the costs and the rewards of medical interventions. Putting a price on the use of medical facilities and personnel for every intervention was a way to increase cost-sensitivity. And as the centre housed both medical and research facilities the question about the overhead costs arose there too: '[S]o at a certain moment, it was buzzing around, like: We have to do performance-based financing because they are doing it too' (financial controller 1).

Second, performance-based financing went beyond performance-based funding in doubling the amount of money that was distributed based on research results. The fund to reimburse departments for their performance was split into two equal parts-one relatively fixed, the other more variable. The first half of the budget was allocated based on the number of associate and full professors employed at the department compared to the total number of full-time jobs at the medical centre. The second half was variable and allocated based on quantitative performance indicators. The range of potential indicators was restricted: 'There are not that many parameters available in the world of research that can also be measured well, to put it that way. So, then...you soon fall back upon the happy few' (financial controller 2). After many rounds of consultation with researchers and financial controllers, the board decided upon the following four performance indicators in 2016: 'acquisition power,' 'doctorates,' 'author force,' and 'score top publications' (see Table 1 for an overview). 40 percent of the variable research budget was reserved for 'acquisition power' and 20 percent for the other three indicators. The overall score of a department vis-à-vis other departments determined its so-called 'market share' in the budget (document 2). In addition to the algorithmic allocation model, these performance indicators were also used to flag the position of the centre in the international research landscape and included in the hiring and promotion guidelines for assistant, associate, and full professors (document 7, 8 and 9).

The first two indicators are concerned with the financial and human resources that departments themselves are able to attract. The indicator 'acquisition power' covers the success of a department in bidding for external grants. The ability to attract such grants has become important in the Dutch academic system over the past

Table 1. Overview of interviews, focus groups, and documents.

\begin{tabular}{|c|c|c|}
\hline $\begin{array}{l}\text { Interviews and } \\
\text { focus groups }\end{array}$ & Participants & Date \\
\hline Interview 1 & Three advisors research policy & December 27, 2017 \\
\hline Interview 2 & Dean & February 8, 2018 \\
\hline Focus Group 1 & Six early career researchers (four PhD students, two postdoctoral researchers) & June 18, 2018 \\
\hline Focus Group 2 & $\begin{array}{l}\text { Eight senior researchers (two assistant professors, four associate professors, } \\
\text { and two full professors) }\end{array}$ & June 182018 \\
\hline Interview 3 & Advisor research policy 1 & December 11, 2018 \\
\hline Interview 4 & Advsisor research policy 2 & December 11, 2018 \\
\hline Interview 5 & Professor 1 & March 13, 2019 \\
\hline Interview 6 & Financial controller 1 & March 19, 2019 \\
\hline Interview 7 & Professor 2 & March 19, 2019 \\
\hline Interview 8 & Financial controller 2 & March 27, 2019 \\
\hline Interview 9 & Professor 3 & April 19, 2019 \\
\hline Interview 10 & Professor 4 & May 16, 2019 \\
\hline Documents & Brief description & \\
\hline Document 1 & Annual report 2017 & \\
\hline Document 2 & Internal memo on allocation model, 2018 & \\
\hline Document 3 & Internal presentation on allocation model, 2015 & \\
\hline Document 4 & Internal presentation on performance indicators, 2016 & \\
\hline Document 5 & Strategic five-year plan, 2018 & \\
\hline Document 6 & Dissertation on early developments in resource allocation, 2009 & \\
\hline Document 7 & Hiring and promotion guideline for assistant and associate professor & \\
\hline Document 8 & Hiring and promotion guideline for full professor & \\
\hline Document 9 & Online presentation of the center & \\
\hline
\end{tabular}


two decades as universities became more dependent on the ability of individual researchers to successfully attract the resources - and the ensuing individual and institutional prestige-to carry out larger research projects. The acquisition power of a department is calculated by taking the three-year average of the grants acquired. The second indicator-'doctorates'-covers the relative success of a department in attracting and supervising PhD students. More than just a reward, the resources are also meant to compensate departments for the insufficient government funding for PhDs. The indicator is calculated by taking the mean number of dissertations defended at a department over the past three years. The final two cover scientific output and are somewhat more laborious. The third indicator is called 'author force' and covers the publication successes of researchers in terms of quantity and impact. The author force of a department is calculated by multiplying the number of articles published over the past three years with the Mean Normalized Citation Score (MNCS). The MNCS is a score that expresses the scientific impact of a set of publications in a particular subfield of research by comparing the citations it managed to attract with what is normal in that subfield. Because articles in (bio)medicine are usually written by a group of researchers, the articles are weighted differently according to the position of the authors. The fourth indicator is the 'score top publications' and covers publications in the highest quartile of scientific journals. The centre uses the ranking of journals by Clarivate Analytics to determine whether a publication belongs to the top one percent-valued highest in the model-or to some other percentile. Again, the department receives money based on the position of the authors on the articles in question (see Table 2).

\section{In Support of Algorithmic Allocation: Market Fairness}

Algorithmic allocation has been the preferred-though contested-model to distribute resources within the cen- tre over the course of two decades. That continuity is the starting point for teasing out some of its normative underpinnings. In particular, this section analyses the place of 'market fairness' in providing a rationale to support algorithmic allocation. That concept of market fairness extends the idea that markets are not just economic phenomena out there in the world, but equally important as a reference point in the normative considerations that we draw upon to support particular ideas of merit and fairness in an organizational or political context (Boltanski \& Thevenot, 2006; Fourcade \& Healy, 2007). Following that line of thought, researchers and policymakers do not literally refer to the university medical centre as a marketplace but do draw upon a range of market-oriented considerations to elaborate on the fairness of this allocation model. Algorithmic allocation was justified negatively in terms of the past injustices it sought to make up for, and justified positively in terms of the principles-exchange, competition, and incentivization - that should prevail when distributing resources fairly and effectively.

In negative terms, market fairness is about eliminating unfair advantages emanating from past decisions to privilege one department at the cost of others. When people have been granted something, one professor remarks, they are not very eager to let go of it. Over time, this creates disparities between departments: '[S]o there are some historical budgets which makes it difficult sometimes....You do run into inequalities. Not everyone is always equal, I say at such moments' (professor 4). The former dean favoured algorithmic allocation because it would ameliorate this situation. As another professor who was close to the whole operation recalls:

That's also what he explicitly said: 'It is all on historical grounds that this department gets this much money and that department that much. That is not fair. I will reconsider it all. And I will put it all in a variable fund and then we will see.' Under the guise of: 'This is fair.' (professor 2)

Table 2. Schematic overview of the allocation model (based on document 2).

\begin{tabular}{|c|c|c|c|c|}
\hline Indicator & Acquisition & Dissertations & Author Force & Top Publications \\
\hline Weight & $40 \%$ & $20 \%$ & $20 \%$ & $20 \%$ \\
\hline Formula & funds & \#doctorates & $(P \times A) \times M N C S$ & $(P \times A) \times Q W$ \\
\hline Explanation & $\begin{array}{l}\text { The amount of } \\
\text { funding acquired } \\
\text { from research } \\
\text { organizations and } \\
\text { patient organizations }\end{array}$ & $\begin{array}{l}\text { The number of } \\
\text { dissertations } \\
\text { defended at a } \\
\text { department }\end{array}$ & $\begin{array}{l}\text { 'P' stands for the number } \\
\text { of articles } \\
\text { 'A' stands for author position: } \\
\text { - First author: } 30 \% \\
\text { - Second author: } 20 \% \\
\text { - Last author: } 20 \% \\
\text { - Other authors: } 30 \% \\
\text { (distributed equally) } \\
\text { 'MNCS' stands for Mean } \\
\text { Normalized Citation Score }\end{array}$ & $\begin{array}{l}\text { 'P' (see previous indicator) } \\
\text { 'A' (see previous indicator) } \\
\text { QW' stands for a ranking of } \\
\text { 'journals based on the Journal } \\
\text { Impact Factor (provided by } \\
\text { Thomson Reuters): } \\
\text { - Top } 1 \% \text { of journals: } 2 \\
\text { - Top } 1-5 \% \text { of journals: } 1,5 \\
\text { - Top } 5-10 \% \text { of journals: } 1,0 \\
\text { - Top } 10-25 \% \text { : } 0,5 \\
\text { - Lower than top } 25 \%: 0\end{array}$ \\
\hline
\end{tabular}


Variability in the funding of departments offered a way out of inequality-but so was quantification. Originally, the historical budgets emerged from rival claims for more resources that were expressed in words, 'there are quite a lot of researchers and they all want to say to the dean: "I conduct the best research in the world." So yes, then quantitative is attractive' (professor 1 ). The quantification of research output offers the dean a way to stay clear of allocation decisions based on verbal claims of research excellence.

The search for quantitative performance indicators was negatively justified with reference to historical budgets but algorithmic allocation was predominantly justified in positive terms. The first positive consideration of market fairness is about the ideal of the organization as being a site of exchange. A key novelty of the allocation model was its integration of both overhead costs and research output. The internal presentation that launched the search for the best performance indicators specified that one should pay a price for the services used-the use of office space and research facilities-and be rewarded for the things one delivers. On the one hand, there is a select set of researchers who take the lead: 'The head of department is responsible for ideas and research (results) and buys resources and support services from resource departments' (document 3). Reasoning from the perspective of the heads of department, a resource is defined as the 'capacity that facilitates or supports the execution of research ideas and projects or that independently engages in activities for the benefit of research' (document 3). On the other hand, there are resource departments who offer goods and services to researchers. Reasoning from the perspective of these service providers, a resource is defined as a 'service or activity for which there is an internal transfer price' (document 3). In building a rationale for algorithmic allocation, the exchange of resources was presented as a key organizational principle.

In addition to exchange, algorithmic allocation builds on the idea of 'achievement through competition' which ensures that the best performing researchers are rewarded while those who perform less well will see their resources decrease. As a matter of fairness, performing in a competitive environment is about doing 'justice' to what someone has accomplished: 'The idea of performance-based financing is an allocation of the benefits that does justice to your achievements' (financial controller 1). The value of competition is also visible in the decision to exclude resources attracted from pharmaceutical companies in the indicator 'acquisition power.' The Centre admitted that acquiring money from industry was an achievement in itself but argued that money from scientific and patient organizations still had a different status because it was 'acquired in (scientific) competition' (document 3). Competition is more than a feature of research management. The long history of algorithmic allocation, one professor says, tells us something about ourselves as researchers too in the sense that 'we are competitive but we do also want to be rewarded for our performance' (professor 4). The recent decision to restrict algorithmic allocation, for instance, thus led to feelings of wrongdoing: 'But now that it is reversed so much you see that we, as staff, say: "Well, yes, if your performance is not financed that is quite difficult too. Because that does not feel right"' (professor 4). In elaborating on that feeling, (s)he adds: 'Well, we too often had the feeling that in particular the people who would grow or did well would get into trouble. Plus...you want to have the feeling that you are rewarded for achieving something' (professor 4).

A third, motivational justification of market fairness is about 'offering incentives for innovation' to departments such that they will be induced to strive for excellence under similar conditions. The explicit objective of algorithmic allocation is 'to reward and stimulate good performances' and to offer 'an incentive for the optimal organization' of the Centre's research infrastructure (document 1; document 4). Under the heading of 'steering on incentives,' the medical Centre spoke of the need to steer on 'the quality of the output' and 'the societal impact of research' as well as the ability to stay 'within the research budget' and be 'in line with the focal areas of the centre' (document 3). Under that same heading, incentives were evoked as a reason to include citation scores of publications in the allocation model: 'As a firm, we wanted a higher MNCS. So how do you do that? Well, you will be steering your department in that direction' (financial controller 1). Again, incentives are not just a matter of research management. They are also evoked by researchers themselves when they express the need for an environment in which innovation is stimulated instead of hampered:

You just have to strike the right balance because you do need the incentives such that people...that people are not part of a too big organizational unity that becomes too inert and bureaucratic. You do want to have the incentives to be innovative and to set up new things. (professor 4)

To be induced to innovate fairly requires uniformity in the opportunities to conduct research. In that regard, incentives also offered an important justification for charging for the overhead costs. This should happen uniformly throughout the organization because departments with more clinical duties might place their healthcare personnel in rooms officially reserved for research if these came at no cost. As one administrator recalls: 'Yes, we have tried beforehand to avoid these kinds of perverse incentives, as we called them at the time, not to strengthen these incentives too' (financial controller 1). All in all, incentives figure prominently in the attempt to build a rationale for algorithmic allocation.

There are clearly pragmatic reasons to opt for an algorithmic model to allocate resources for (bio)medical research. The financial reorganization in healthcare, for 
instance, was an important pragmatic factor for charging for the overheads in research too. The weight of acquisition power in the model, moreover, is not just to induce researchers to attract as many external grants as possible-though that is certainly part of it-but also because these grants have to be matched to internal resources in order to be viable (document 3 ). But placing these pragmatic reasons aside, this section demonstrated how both administrators and researchers justify the need for algorithmic allocation in marketoriented terms: to break with the alleged unfairness of historical budgets; to maintain the idea of achievement through competition; to incentivize innovation under similar conditions, and to do so in an organizational context of exchange where prices and responsibilities are well-defined.

\section{Challenging Algorithmic Allocation: Epistemic Fairness}

Algorithmic allocation became controversial soon after its implementation. The biomedical departments, in particular, had difficulties in attracting external grants and their resources further declined-due to the weight of acquisition power in the model-until their very survival was at stake (financial controller 1 and 2; professor 2). In 2018, the new board of directors decided to reduce the variable budget from 50 to 10 percent and to limit departmental competition (document 2). The decision to put algorithmic allocation on hold-instead of letting departments go bankrupt-shows that market fairness only reaches so far into matters of research management. In fact, researchers and administrators have brought a range of issues to the fore to problematize algorithmic allocation and its normative underpinnings. These considerations of 'epistemic fairness' all hinge on the idea that there are differences in the practices of producing scientific knowledge (Borgman, 2017; Franssen et al., 2018; Hessels et al., 2019; Knorr-Cetina, 1999). Or as one professor expressed it: 'Yes, I do not mind the discussion about benchmarking, about comparisons. You have to be proud of your output. But you have to look a little bit at the diversity, at how science is done' (professor 1). Biomedical scientists, for one, work primarily in laboratories on a wide range of biological processes at the level of cells, proteins, and DNA. As preclinical or 'basic' research, biomedicine is often quite far removed from direct healthcare applications and requires a lot of equipment, animals, and chemicals. The health sciences, on the other hand, are a less capital-intensive branch of research-computers and databases suffice here. Engaged in the science of large numbers, health scientists study the association between health-related variables in large cohorts of people. The health sciences have a role in some screening programs but are often more aligned with prevention-and hence with regional and national policymaking - than with clinical practice. Such epistemic differences lead to four considerations of fairness that problematize-or directly challenge-the market-oriented justifications which have been analysed so far.

To start with, the various departments differ significantly in publication output and their typical citation impact. In certain fields, individual journal publications can be produced with relatively little effort. Writing an article can, for example, entail performing a set of relatively standardized statistical analyses applied to data that were not generated by the authors themselves. This contrasts with the significant amounts of effort that can go into conducting more practical experimental studies performed in other fields: 'If you are doing cell biology, it's extremely difficult to get a paper. And if you work in big databases, then you can get twenty papers. So, I think especially universities should understand and acknowledge that' (junior researcher 1 ). The administrative staff is also aware of differences in publication practices:

As a joke I always say, I exaggerate of course: You have a fundamental-orientated department who work their butts off for one publication. And you have a life science department who can put its computer on in the morning and, hop, there we have another publication from the database....And what you notice then-that is, if you don't discriminate between different types of research-is that fundamental research is being eaten up because they have less output. (financial controller 2)

Our respondents also touched on more subtle aspects of epistemic fairness in the use of publication-related metrics. One administrator, for example, mentioned the example of a field whose relatively small-scale organizational structure has resulted in very high MNCS scores. Conversely, in some cases, citation scores are normalized for a broader set of specialities that can make the output of a given department look underwhelming in comparison.

If you are in a niche-field like child medicine, to name one, you never have a high MNCS score because you are competing in internal medicine, you know. So they can never score on this....So in that sense, it is unfair competition. (financial controller 2)

Furthermore, some of our respondents were concerned with the fact that a focus on output and citation results makes cooperation among departments less visible: 'But you can ask yourself: Okay, this department does not publish that much but they are actually pretty important for the medical centre because they have this specific expertise that many other departments, in fact, do make use of' (professor 2). A department, for instance, might provide data or other resources that are crucial for the work of others but 'if you are stuck to performancebased financing [then] you are at a point of losing such a department' (professor 2). 
Secondly, scientists also clearly experience the competition for a larger market share as something that exerts a certain pressure on them: 'The department gets a financial kind of award, I guess, per publication, right?...So that's where the pressure starts, right?' (junior researcher 2). In their eyes, this leads them away sometimes from fair and responsible behaviour. For one, it informs publication practices and increases the rivalry over authorship positions:

There is the performance-based financing, so it will get worse and worse because we get the [name scientometric institute], the citation, the MNCS. For our department, for example, it will be much better to publish in lower impact [journals], because it is too difficult [otherwise], and have more papers. And then we should claim all the first and lasts because otherwise our department will lose money for research and we have to fire people. (senior researcher 1)

In the focus group setting, another senior researcher responded by saying that the allocation model leads to a very particular kind of creativity: 'We all are creative then to make sure we get this performance-based financing, this additional funding. But is it really responsible science? That's the question' (senior researcher 2). One of the key ways to be responsible is to address a (scientific) audience that your results are most relevant for. Due to the exclusive focus on publications in the highest quartile of journals, however, other kinds of considerations easily take over. One of the things that (bio)medical scientists reflect upon is the instrumental way in which they seize upon epistemic differences between fields: 'Q1 is determined for a disciplinary field. So you shop around there. So sometimes it is: Oh, now I need to publish in a biology journal because there I can still publish in Q1, whereas in immunology it is not possible' (junior researcher 3 ). Adding to this practice of 'shopping around,' another researcher points to a tension between publishing in higher-ranked journals and finding a suitable audience:

But then, if you think back on the responsible researcher and you shop around because you want to publish in the Q1 journals. But it might not be the journal which is most suitable for your research and with the readers....It is something strange you do.' (junior researcher 4)

Differences in the perception of the value of different publication outlets-again bound up with field differences-also permeate the relationship between junior and senior researchers:

For me, it's actually quite tricky....For my future, it is better to publish in more scientific journals. But it's easier to publish in Q1 in less scientific journals. So my PI [principal investigator] wants to publish in these journals while I want to publish in the more scientific journals. (junior researcher 1 )

In reflecting upon daily decision-making on the scientific shop floor, the algorithmic allocation model is explicitly related to the struggle over authorship positions and to attempts to 'creatively' seize upon epistemic differences in publication and citation patterns between different (bio)medical fields. The placing of authorship within the allocation model at least gives institutional legitimacy to the (perceived) pressure to secure good authorship positions in order to add to the market share of the department-but it might equally contribute to a struggle over authorship positions.

A third important aspect of epistemic fairness relates to an unequal ability of departments to attract resources beyond the confines of the medical Centre. The reason for this is the highly diverse structure of academic and commercial funding opportunities across fields.

For [some] discipline[s] it is way easier to acquire external funding. Of course, there is a lot of competition but the total availability of funding for oncology, for example, is much larger than for medical ethics or plastic surgery. How can you use the same measuring rod? (research policy advisor 1)

One interviewee contends that differences in the access to external resources make for 'a really difficult balance' in the allocation model because 'some research can get money more easily than other research' (professor 4). This interviewee perceives this as having to do with how 'sexy' the research is: 'I always say that you just have an easier time when you do something with pitiful children or cancer' (professor 4). More fundamentally, access differs between clinical research on the one hand and basic research in biomedicine and the health sciences on the other. Research with greater relevance for clinical practice, for instance, is depicted as a 'completely different branch of sports' due to the access that the clinical departments have to the resources of pharmaceutical companies:

$[Y]$ ou also have to realize...that big pharma is on top of it; it pours a lot of money into it. And a lot of money goes specifically to these departments. Yeah, they can, of course, deliver these pharma outcomes, but they can also partly use that money and fund other research projects that would maybe not get funded otherwise. (professor 2)

A further complicating factor is that according to some of our subjects, more fundamental forms of research tend to encounter difficulty in convincing patient organizations of the value of their work. This was perceived as an additional source of imbalance in the overall distribution of funds across (bio)medical research, with the current algorithmic allocation system reinforcing the problem: 
And in my field-I'm working on a pretty molecular level, so patients, of course, don't see the relevance in that....So what's happening now, looking at all the VENI's and VIDI's [major Dutch research grants], is that a lot of proposals closer to the clinic get the money because, whatever....And now we don't really notice the effect but in ten years we will definitely notice it. (junior researcher 1 )

Fourth and finally, our interviewees point to differences in the average duration of doctorates between fields and terms of how successful departments can claim to be in supervising graduate students. As a general rule, doctorates in clinical fields tend to take less time than in biomedical fields:

Concerning doctorates, that takes five years on average at a biomedical department while it takes three years in the clinic....So you actually have very specific norms per group or per research field about what you need to really do. Because if you have the same measuring rod for everything, then, yeah, you destroy more than you achieve according to me. (financial controller 1 )

Interviewees account for such differences by referring to the greater degree of unpredictability of laboratorybased research. One professor explained that unexpected outcomes of experiments are common and can significantly delay graduation or even lead students to give up while this is less common in the more clinical areas:

Look, we, of course, have departments...where it is way easier to channel PhD students. It is a kind of doctorate factory. And in the laboratory, it is plodding on and if something fails then a whole doctorate might fail. That is quite a difference. (professor 4)

In summary, the considerations presented in this section draw on perceived differences in the practices of knowledge production to confront the quantitative indicators at the heart of algorithmic allocation (see also Rushforth \& de Rijcke, 2015). Following this line of reasoning, departments no longer appear as organizational units that can compete fairly based on a set of uniform performance indicators covering doctorates, external grants, and the number and scientific impact of publications.

\section{Conclusions}

In our article, we addressed an analytical question central to higher education as it is managed and experienced nowadays: What kinds of normative consideration do researchers and administrators draw upon to justify or challenge algorithm-based allocation? To answer that question, we untangled two rival notions of fairness that were at play in research management. The long history and continuous importance of performance-based financing at our university medical centre first led us to four considerations of market fairness: Eliminating the arbitrary interference that has previously privileged some departments at the cost of others; installing achievement through competition as insurance that the best departments were rewarded while those who performed less well saw their resources decrease; introducing incentives to induce innovative research and to stimulate departments to excel under similar conditions; and reconfiguring the research organization as a site of exchange where people pay for the services used and receive money for the things they deliver.

The decision to put algorithmic allocation on hold led us to the second series of normative considerations that problematized the idea that it resulted in a fair distribution of resources. These considerations of epistemic fairness, as we called them, build on the idea that a university medical centre might be unified in its focus on health and disease but very diversified in its cultures of knowledge production and their affordances and constraints (Borgman, 2017; Franssen et al., 2018; Hessels et al., 2019; Knorr-Cetina, 1999). Differences in the publication practices between different (bio)medical fields was the first normative issue brought to the fore as a challenge to the alleged fairness of the allocation model. In addition, researchers linked the insistence on Q1 publications and the importance of authorship positions in the model to struggles between researchers to secure the best position and to tensions at the heart of their decision to publish in one journal or another. Third, researchers and administrators pointed to differences in the ability of departments in different fields to attract external resources. Finally, they singled out the 'doctorate' as a research trajectory that had a different temporal and risk-related meaning for different PhD students and departments. When we bring these considerations together, the organization appears as something more than a site of competition, incentivization, and exchange. Instead, those with decision-making power should account for differences in publication practices, doctoral research, and access to resources, and acknowledge that research is not just a matter of competitive achievements of otherwise homogeneous departmental units.

The case of algorithmic allocation at a university medical centre does not stand on its own. It fits in with broader trends of quantification, marketization, and algorithm-based decision making in higher educationas well as in society more broadly. On the one hand, our analysis corroborates earlier findings about the importance of indicators and rankings for research management as well as the spread of market-oriented ideals and practices in the current organization of research (Hammarfelt et al., 2017; Paradeise \& Filliatreau, 2016; Rushforth \& de Rijcke, 2015, 2017; Sauder \& Espeland, 2009). By untangling considerations of market fairness, we were able to better understand the appeal of competition and quantitative performance indicators for allocation purposes. On the other hand, however, our analysis of epistemic fairness shows that we should be 
careful in depicting higher education as populated by 'market universities' fully enmeshed in 'epistemic capitalism' (Berman, 2012; Birch, 2017; Fochler, 2016; Slaughter \& Rhoades, 2009). Although these trends definitely influence research organizations, they remain heterogeneous institutions in which rival normative considerations are at play (Paradeise \& Thoenig, 2018; Rushforth et al., 2018; Whitley, Gläser, \& Engwall, 2010). Beyond the specifics of the case, our analytic distinction between market fairness and epistemic fairness thus provides insights into the relative instability and (potential) room for manoeuvre of research organizations. The normative tension we discerned offers a way into the internal dynamics of organizational debates and-possibly-a way out of the limitations that marketization, quantification, and algorithms impose.

The current state of the allocation model at the Centre provides an interesting test case of how to deal with normative tensions in a broader 'algorithmic culture' (Striphas, 2015). The future of performance-based financing at the centre is still undecided. Algorithmic allocation is currently severely restricted, but the board of directors has tasked a special committee to reconsider performance-based financing and there is a push from the heads of department to slowly bring it up to its former level. The broader literature on computation and algorithms could offer interesting perspectives for consideration by decision-makers in higher education and elsewhere (Berman \& Hirschman, 2018; Finn, 2017; van Dijck, 2013). We flag two specific sources of concern. The first concerns the way institutions should sustain wider legitimacy and be held 'algorithmically accountable' (Couldry, 2016). The partial or full delegation of human decision making to automation raises profound questions about responsibility and accountability for the outcomes of these decisions. Are decision-makers fully able to understand the algorithms and their consequences? And can they still explain to others that the decision made sense when they are prompted to do so? The second issue concerns the way to deal with rival considerations of fairness in designing, implementing, and reviewing algorithms. Our case demonstrates that there are crucial differences in the way people justify or problematize algorithm-based decision making. Can we expect algorithms to ever resolve the normative tensions that divide organizations and human societies? Or do algorithms aggravate such tensions because some considerations are more easily embodied while others are pushed to the side? These two sources of concern, accountability and normativity, are not so easily addressed. But we do expect them to appear and reappear whenever and wherever algorithm-based decision making predominates-in higher education institutions as well as in other areas of social life.

\section{Acknowledgments}

The research conducted for this article was funded by The Netherlands Organisation for Health Research and
Development (ZonMW). We would like to thank the reviewers for their critical and constructive comments.

\section{Conflict of Interests}

The authors declare no conflict of interests.

\section{References}

Berman, E. P. (2012). Creating the market university: How academic science became an economic engine. Princeton, NJ: Princeton University Press.

Berman, E. P., \& Hirschman, D. (2018). The sociology of quantification: Where are we now? Contemporary Sociology, 47(3), 257-266.

Birch, K. (2017). Rethinking value in the bio-economy: Finance, assetization and the management of value. Science, Technology \& Human Values, 42(3), 1-31.

Boltanski, L., \& Thevenot, L. (2006). On justification: Economies of worth. Princeton, NJ: Princeton University Press.

Borgman, C. L. (2017). Big data, little data, no data: Scholarship in the networked world. Cambridge, MA: MIT Press.

Couldry, N. (2016). What's at stake in algorithmic accountability. Media@LSE blog. Retrieved from https://blogs.Ise.ac.uk/medialse/2016/04/28/ whats-at-stake-in-algorithmic-accountability

Finn, E. (2017). What algorithms want: Imagination in the age of computing. Cambridge, MA: MIT Press.

Fochler, M. (2016). Variants of epistemic capitalism: Knowledge production and the accumulation of worth in commercial biotechnology and the academic life sciences. Science, Technology \& Human Values, 41(5), 922-948.

Fourcade, M., \& Healy, K. (2007). Moral views of market society. Annual Review of Sociology, 33, 285-311.

Franssen, T., Scholten, W., Hessels, L. K., \& de Rijcke, S. (2018). The drawbacks of project funding for epistemic innovation: Comparing institutional affordances and constraints of different types of research funding. Minerva, 56(1), 11-33.

Hammarfelt, B., de Rijcke, S., \& Wouters, P. F. (2017). From eminent men to excellent universities: University rankings as calculative devices. Minerva, 55(4), 391-411.

Hessels, L. K., Franssen, T., Scholten, W., \& de Rijcke, S. (2019). Variation in valuation: How research groups accumulate credibility in four epistemic cultures. Minerva, 57(2), 127-149.

Knorr-Cetina, K. (1999). Epistemic cultures: How the sciences make knowledge. Cambridge, MA: Harvard University Press.

Paradeise, C., \& Filliatreau, G. (2016). The emergent action field of metrics: From rankings to altmetrics. In $\mathrm{E}$. Berman \& C. Paradeise (Eds.), University under Pressure: Research in Sociology of organizations series (pp. 87-128). Bingley: Emerald Group. 
Paradeise, C., \& Thoenig, J. C. (2018). Higher education institutions as strategic actors. European Review, 26(Supp. 1), 57-69. https://doi.org/10.1017/ S1062798717000540

Rushforth, A. D., \& de Rijcke, S. (2015). Accounting for impact? The journal impact factor and the making of biomedical research in the Netherlands. Minerva, 53(2), 117-139.

Rushforth, A. D., \& de Rijcke, S. (2017). Quality monitoring in transition: The emerging challenge of evaluating translational research programs in academic biomedicine. Science and Public Policy, 44(4), 513-523.

Rushforth, A. D., Franssen, T. P., \& de Rijcke, S. (2018). Portfolios of worth: Capitalizing on basic and clinical problems in biomedical research groups. Science, Technology, \& Human Values, 44(2), 209-236.
Sauder, M., \& Espeland, W. N. (2009). The discipline of rankings: Tight coupling and organizational change. American Sociological Review, 74(1), 63-82.

Slaughter, S., \& Rhoades, G. (2009). Academic capitalism and the new economy: Markets, state and higher education. Baltimore, MD: Johns Hopkins University Press.

Striphas, T. (2015). Algorithmic culture. European Journal of Cultural Studies, 18(4-/5), 395-412.

van Dijck, J. (2013). The culture of connectivity: A critical history of social media. Oxford: Oxford University Press.

Whitley, R., Gläser, J., \& Engwall, L. (Eds.). (2010). Reconfiguring knowledge production: Changing authority relationships in the sciences and their consequences for intellectual innovation. Oxford: Oxford University Press.

\section{About the Authors}
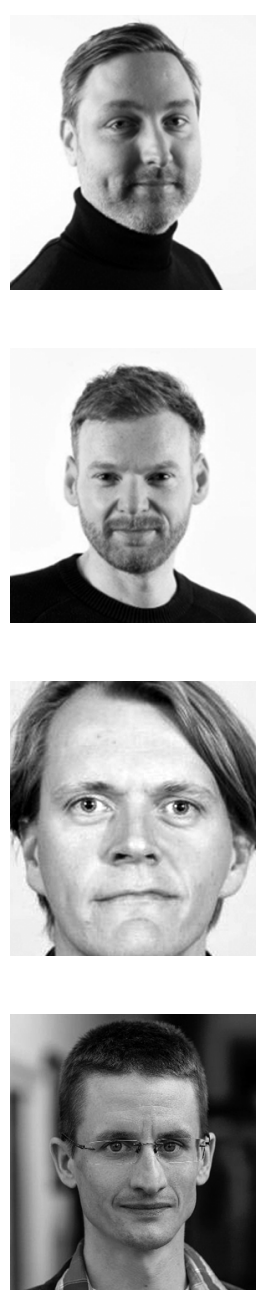

Govert Valkenburg is a Senior Researcher in Science, Technology and Society Studies at the Department of Interdisciplinary Studies of Culture of the Norwegian University of Science and Technology. He currently studies knowledge dynamics in innovation processes and connects them to political theories. His research has covered energy transitions, privacy and security technologies, and human genomics. He was recently awarded a personal Researcher Project grant by the Research Council of Norway, for research into knowledge equity in the securitization of critical infrastructures.

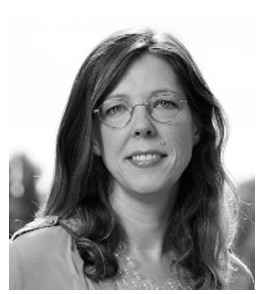

Sarah de Rijcke is Professor in Science and Evaluation Studies and Scientific Director at the Centre for Science and Technology Studies in Leiden. Chair of the research group. She also is Co-Chair of Research in Research Institute (RoRI). Sarah specialises in social studies of research evaluation, and has published widely on the topic of the relations between quality control mechanisms and knowledge production in different fields. She has also developed a strong international public academic presence. 